
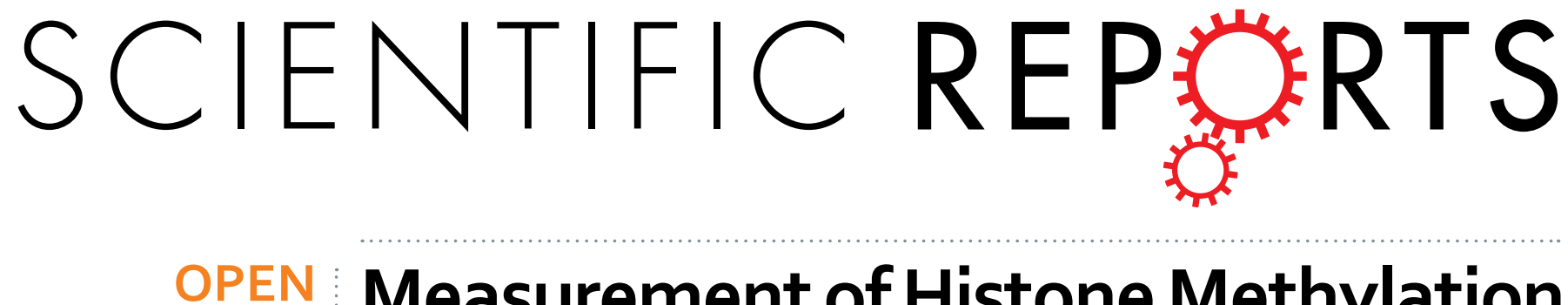

\title{
Measurement of Histone Methylation Dynamics by One-Carbon Metabolic Isotope Labeling and High-energy \\ Collisional Dissociation Methylation Signature Ion Detection
}

Received: 22 February 2016

Accepted: 21 July 2016

Published: 17 August 2016

\author{
Hui Tang ${ }^{1}$, Bing Tian ${ }^{2,3}$, Allan R. Brasier ${ }^{2,3}$, Lawrence C. Sowers ${ }^{1}$ \& Kangling Zhang ${ }^{1,3}$
}

Accumulating evidence suggests that cellular metabolites and nutrition levels control epigenetic modifications, including histone methylation. However, it is not currently possible to measure the metabolic control of histone methylation. Here we report a novel detection method to monitor methyl transfer from serine to histones through the one-carbon metabolic pathway, using stable-isotope labeling and detection of lysine methylation signature ions generated in high-energy-dissociation (HCD) tandem mass spectrometry. This method is a long-needed tool to study the metabolic control of histone methylation.

Like DNA methylation, histone methylation plays an important role in the regulation of gene expression ${ }^{1,2}$. The methylation reaction occurs via a methyltransferase with S-adenosyl-methionine (SAM) as cofactor ${ }^{3,4}$. SAM is synthesized from ATP and methionine. In addition to its production from other sources, such as cellular synthesis from L-cysteine and L-aspartate ${ }^{5}$, nutrition and protein degradation ${ }^{6}$, methionine can be synthesized via the one-carbon metabolic pathway ${ }^{7,8}$. This pathway is coupled to two metabolic cycles: the folate cycle, in which a one-carbon unit from serine or glycine is transferred to tetrahydrofolate (THF) to form 5-methylene-THF (5-meTHF), and the methionine cycle. The latter cycle produces methionine by remethylation of homocysteine from a methyl group provided by 5 -meTHF, catalyzed by methionine synthase and its cofactor, vitamin $B_{12}$. This methionine is metabolized to SAM, which serves as the rate-limiting methyl donor to major methylation substrates including DNA and histones (Fig. 1). Metabolites of folate, THF and 5-meTHF in the folate cycle are the precursors of pyrimidines and purines, which are two of the building blocks of nucleic acids (Fig. 1). Therefore, the one-carbon metabolism pathway is also linked with DNA replication during cell development.

Though histone methylation and demethylation are largely achieved by well-studied methyl writers (methyltransferases) and erasers (demethylases), the control of cofactor abundance is largely unexplored, despite the proof-of-principle that histone methylation can be detected using metabolic labeling with radioactive ${ }^{14} \mathrm{C}$-(methyl)-labeled methionine ${ }^{9}$. Without question, the dynamics of methylation reactions are regulated by metabolic equilibrium and cellular nutrition. Metabolic studies on the dynamics of DNA methylation have previously been conducted by stable-isotope labeling of methionine in replicating cultured cells and subsequent mass spectrometry measurements ${ }^{10}$. However, metabolic studies on the dynamics of histone modifications have not been performed. Here we report a novel detection method that measures the intensities of the methylation signature Ions located in the low-mass region of the HCD MS2 spectra, which avoids the need for super resolving power to separate isotopologues in the precursor ion MS1 spectra. Instead, by employing an isotope-labeling and detection strategy similar to previous approaches developed for the separation of TMT10 reporters and neutron-encoding ions (NeuCode) ${ }^{11,12}$, we show that Orbitrap instruments have sufficient resolving power to detect a one Dalton increase in heavy isotopic ions in a methylated lysine containing a cluster of ${ }^{15} \mathrm{~N} /{ }^{13} \mathrm{C} /{ }^{2} \mathrm{H}$ isotopes, allowing them to be separated and their intensities accurately measured. We demonstrate that, using

${ }^{1}$ Department of Pharmacology \& Toxicology, University of Texas Medical Branch, Galveston, Texas, 77555, USA. ${ }^{2}$ Institute for Translational Sciences, UTMB, Galveston, Texas, 77555, USA. ${ }^{3}$ Sealy Center for Molecular Medicine, UTMB, Galveston, Texas, 77555, USA. Correspondence and requests for materials should be addressed to K.Z. (email: kazhang@utmb.edu) 


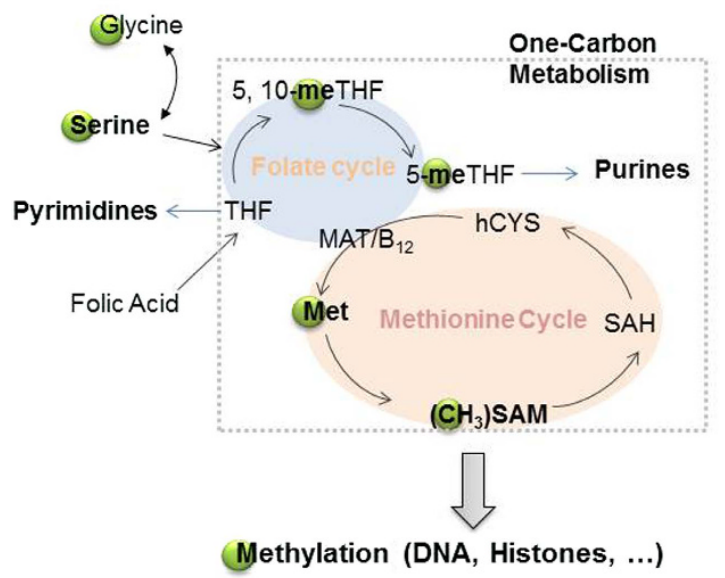

Figure 1. Methyl transfer from serine or glycine to DNA/histones through the one-carbon metabolic pathways. THF: tetrahydrofolate; 5, 10-meTHF: 5, 10-methylene-THF; 5-meTHF: 5-methylene-THF; MAT: methionine synthase; Met: methionine; SAM: S-adenosyl-methionine; SAH: S-adenosylhomocysteine; hCYS: homocysteine.

this method, we are able to monitor methyl transfer from serine to histones through the one-carbon metabolic pathway.

\section{Results and Discussion}

The difference between ${ }^{15} \mathrm{~N}(15.0001 \mathrm{amu})$ and ${ }^{14} \mathrm{~N}(14.0031 \mathrm{amu}),{ }^{13} \mathrm{C}(13.0034 \mathrm{amu})$ and ${ }^{12} \mathrm{C}(12.0000 \mathrm{amu})$, and ${ }^{2} \mathrm{H}(2.0141 \mathrm{amu})$ and ${ }^{1} \mathrm{H}(1.0078 \mathrm{amu})$ is $0.9970,1.0034$, and $1.0063 \mathrm{amu}$, respectively. When being incorporated into a peptide, this tiny difference among +1 isotopes in the precursor ion and its major fragments, $b$ and y ions, becomes almost indistinguishable and can hardly be resolved by a conventional mass spectrometer - even the Orbitrap running in a general LC-MS/MS mode. For illustration, we grew THP1 cells in medium containing $0.5 \mathrm{mM} 2,3,3-{ }^{2} \mathrm{H}$ - serine for up to $96 \mathrm{hr}$ and used a QExactive mass spectrometer to analyze $\mathrm{H} 3$ K9 mono-methylated peptides isolated after tryptic digestion of core histones. The calculated doubly-charged mono-isotopic mass of the precursor ion of this peptide was 479.27799 (100\%), and the mass values of its +1 isotopic peak containing an overlapped cluster with a single isotope were $479.77650\left({ }^{15} \mathrm{~N}, 5.2 \%\right), 479.77966\left({ }^{13} \mathrm{C}\right.$, $43.3 \%)$ and $479.78113\left({ }^{2} \mathrm{H}, 0.85 \%\right)$, respectively ${ }^{13}$; it should be noted that the contribution from ${ }^{18} \mathrm{O}$ is very small, and therefore not included in this calculation. As shown in the parentheses, ${ }^{13} \mathrm{C}$ is the most naturally abundant heavy isotope in the peptide, and contributes $43.3 \%$ relative to the mono-isotope. This natural isotope distribution pattern is reflected in the spectra corresponding to histones extracted from the medium without heavy serine (Fig. 2, $0 \mathrm{hr}$ ). During the course of incubation with heavy serine, one-carbon ${ }^{2} \mathrm{H}-\mathrm{CH}_{3}$ and to a significantly lesser degree ${ }^{2} \mathrm{H}_{2}-\mathrm{CH}_{3}$ are progressively transferred from serine to histones (Figs 1 and 2), so the proportion of ${ }^{2} \mathrm{H}$ in the isotopic peaks is increasingly enriched. As shown in Fig. 2, most obviously at $96 \mathrm{hr}$, the isotopic peaks from +1 to +4 are significantly enhanced. It is not trivial to calculate the incremental intensity due to the incorporation of ${ }^{2} \mathrm{H}$ from one experiment to another, nor can the accuracy of the calculation be ensured without separating the overlapping isotopic peaks. Separation of the cluster of isotopic peaks into single isotope-containing peaks requires huge resolving power. For instance, bottom-line separation of the aforementioned three +1 isotopic peaks needs at least 320,000 FWHM (Full Width at Half Maximum), based on a semi-empirical equation we used (Supplemental Calculation 1). The outcome of this calculation is fairly close to the FWTM (Full Width at $10 \%$ Maximum) value calculated by Coon's equation derived from Gaussian peak shape modeling (Figure S1) ${ }^{12}$. However, even if this isotopic cluster can be separated, the portion of incorporated ${ }^{2} \mathrm{H}$ from methylated lysine cannot be precisely determined from the MS1 spectrum because the peptide has one serine and two glycines (which can be synthesized from serine) that can also contribute ${ }^{2} \mathrm{H}$ to the isotopic pool.

The resolving power required for isotopic peak separation is proportional to the size of the molecules being separated; the smaller the molecules with close masses, the lower the resolving power needed to separate them. This concept can be applied for isolation of stable isotope-labeled methylated lysine in peptides. As we know, mono-methylated lysine generates a unique immonium ion at $m / z 98.0963^{14,15}$, and its +1 isotopes with single ${ }^{15} \mathrm{~N},{ }^{13} \mathrm{C}$, or ${ }^{2} \mathrm{H}$ have $\mathrm{m} / z$ of $99.0932,99.0996$, and 99.1023 , respectively. Theoretically, separation of these +1 peaks only needs $\sim 35,000 \mathrm{FWHM}$; an Orbitrap instrument is sufficient to provide this resolving power. As we expected, these ions produced from the aforementioned $\mathrm{H} 3 \mathrm{~K} 9$ monomethylated-K14 acetylated peptide can be separated by an Orbitrap mass spectrometer with the resolution of MS2 scan set at 70,000 FWHM (Fig. 3). It is clearly seen that heavy protons were transferred from $2,3,3-{ }^{2} \mathrm{H}$ - serine to the $\mathrm{CH}_{3}$ methyl group of methylated lysine immonium ions as high as $3.7 \%\left(\mathrm{C}_{6} \mathrm{H}_{11} \mathrm{DN} / \mathrm{C}_{6} \mathrm{H}_{12} \mathrm{~N}\right)$ at $96 \mathrm{hr}$, compared with $0.1 \%$ at $0 \mathrm{hr}$, which approximately equals the natural isotopic distribution (Fig. 3). Of course, $3.7 \%$ is itself not a large number, but considering it represents more than a 25 -fold increase from the natural abundance $(0.14 \%)$, it is a tremendous change that renders the tracking and quantification of isotope-labeled methylation no longer difficult. However, the change from $0.1 \%$ to $3.7 \%$ for ${ }^{2} \mathrm{H}$ in $\left(\mathrm{CH}_{3}\right)$ alone would not cause significant alteration of the isotopic distribution in the precursor ion spectrum. The greatly increased isotopic peak intensities largely arise from ${ }^{2} \mathrm{H}$-glycine (which can donate one ${ }^{2} \mathrm{H}$ ) 

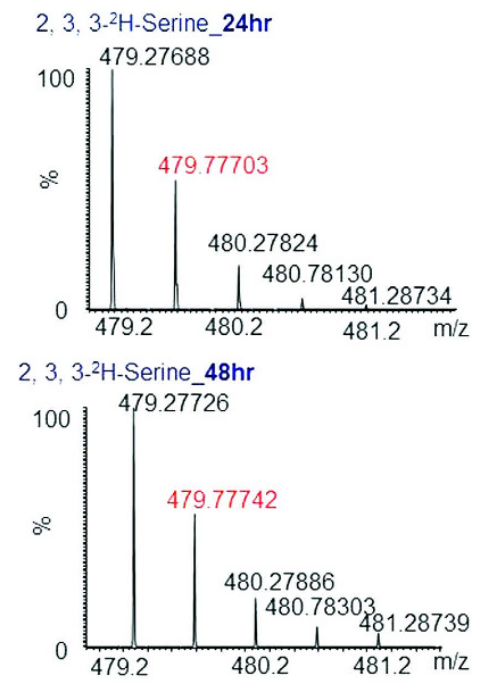

2, 3, 3-2 $2 \mathrm{H}$-Serine_72hr

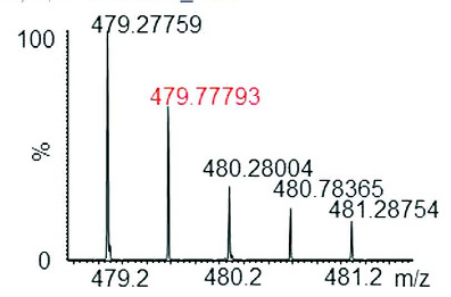

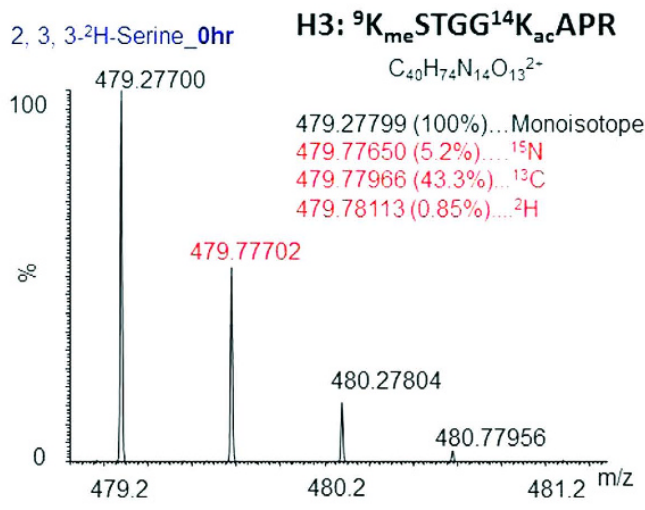

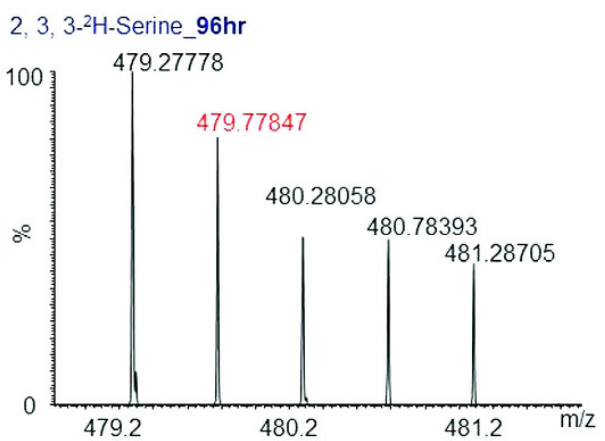

Figure 2. Isotopic distribution of the precursor ions in the HCD spectrum of H3 K9-mono-methyated and K14-acetylated peptides. Shown counterclockwise are the spectra of the $\mathrm{H} 3$ peptides digested from histones

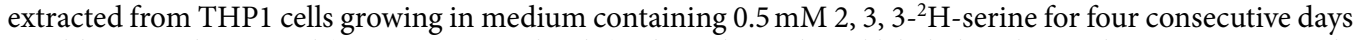
in addition to the control $(0,24,48,72$, and $96 \mathrm{hr})$. The red-numbered labeled peaks are the +1 isotopic peaks, overlapping with a cluster of three major isotopes $\left({ }^{15} \mathrm{~N},{ }^{13} \mathrm{C}\right.$, and $\left.{ }^{2} \mathrm{H}\right)$ whose calculated mass values and natural occupancies (shown in nearby parentheses) are listed in the $0 \mathrm{hr}$ spectrum.

converted from $2,3,3-{ }^{2} \mathrm{H}$ - serine for the +1 and +2 peaks, and from both ${ }^{2} \mathrm{H}$-glycine and 2, 3, 3- ${ }^{2} \mathrm{H}$ - serine (which can donate three ${ }^{2} \mathrm{H}$ ) for the +3 and +4 peaks, as we can see in Fig. 2. Thus, the advantage of monitoring methyl-transfer via detection of the immonium ion is clearly demonstrated.

Due to oversaturation of the six-member ring structure by tri-methyl amine, tri-methylated lysine cannot form a mono-methylated lysine-like ammonium ion; it instead generates a prominent "neutral-loss" trimethylammonium ion $\left[\mathrm{NH}\left(\mathrm{CH}_{3}\right)_{3}, \mathrm{~m} / z 60.0811\right]^{14,15}$. Like mono-methylated lysine, this small ion and its stable-isotopes +1 ions $\left({ }^{2} \mathrm{H}\right.$ (or D), ${ }^{13} \mathrm{C}$, and $\left.{ }^{15} \mathrm{~N}\right)$ can be distinguished by a high-resolution Orbitrap mass spectrometer, and the ${ }^{2} \mathrm{H}$-methyl $\left(\mathrm{CH}_{2} \mathrm{D}\right)$ group $\left(\mathrm{m} / z\right.$ 61.0873) transferred from $2,3,3-{ }^{2} \mathrm{H}$-serine to tri-methylated lysines can be monitored accordingly. Since these ions are relatively small, a resolution of 35,000 is sufficient to separate them. This concept was also tested by analyzing histone H4 K20 tri-methylation in THP1 cells that were grown in culture

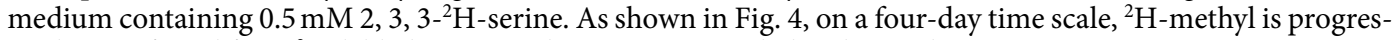
sively transferred from ${ }^{2} \mathrm{H}$-labled serine to the $\mathrm{H} 4 \mathrm{~K} 4$ tri-methylated peptide.

To test the applicability of this method, we applied the above approach to cell differentiation/proliferation studies. In our previous proteomics analysis of protein expression pathways in human leukemic monocyte-U937 cell differentiation, down-regulation of proteins associated with the replication fork was found among the significantly disturbed pathways induced by phorbol myristate acetate (PMA), suggesting that PMA inhibits chromatin remodeling-mediated DNA replication ${ }^{16}$. DNA replication is coordinated with DNA synthesis at the replication fork, which requires an adequate supply of pyrimidines and purines that are the building blocks of four deoxyribonucleotide triphosphates (dNTP's) required for DNA synthesis. Pyrimidines and purines are synthesized, respectively, from THF and 5-meTHF which are originally derived from folate acid and regulated by the serine/glycine one-carbon metabolic pathways (Fig. 1). This information garnered from previous experiments would predict an impeded one-carbon metabolism pathway in the PMA-differentiated cells that has never been explored. Further, an impeded one-carbon metabolism pathway in PMA-treated cells would result in a decrease in methionine which is synthesized by transmethylation from 5-meTHF to hCYS in the presence of methionine synthase (MAT) and cofactor vitamin $B_{12}$ (Fig. 1). After a domino effect, SAM would be depleted and then, histone methylation is decreased. Following this lead, we could evaluate the DNA synthesis status by indirectly measuring methyl transferring rate from serine to histones (or DNA). Accordingly, we repeated our PMA-differentiation experiments by culturing U937 cells in the medium containing $0.5 \mathrm{mM} 2,3,3-{ }^{2} \mathrm{H}$-serine and measuring histone methylation by ${ }^{2} \mathrm{H}$ incorporation using the above-described techniques. As shown in Fig. 5A, the transmethylation rate $\left[\mathrm{CH}_{2} \mathrm{D} / \mathrm{CH}_{3}(\%)\right]$ at five targeted histone monomethylation sites decreased nearly 2 -fold 
A

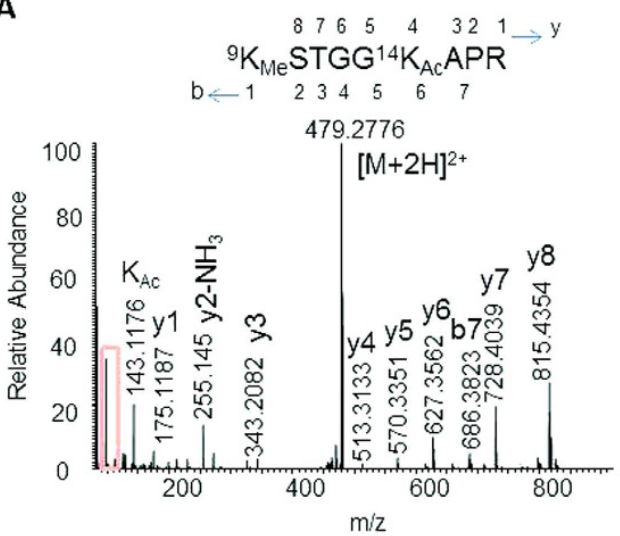

\begin{tabular}{|r|c|c|c|c|}
\hline \multirow{2}{*}{$M / Z$} & \multirow{2}{*}{ Formula } & \multirow{2}{*}{ Nature\% } & \multicolumn{2}{|c|}{ H3K9me } \\
\cline { 4 - 5 } & & & Ohr & $96 \mathrm{hr}$ \\
\hline (1) 98.0963 & $\mathrm{C}_{2} \mathrm{H}_{12} \mathrm{~N}$ & 100 & 100 & 100 \\
\hline 99.0932 & $\mathrm{C}_{2} \mathrm{H}_{12}{ }^{15} \mathrm{~N}$ & 0.37 & 0.28 & 0.26 \\
\hline 99.0996 & $\mathrm{C}_{5}{ }^{13} \mathrm{CH}_{12} \mathrm{~N}$ & 6.49 & 6.45 & 5.28 \\
\hline (2) 99.1023 & $\mathrm{C}_{6} \mathrm{H}_{11}{ }^{2} \mathrm{DN}$ & 0.14 & 0.07 & 3.79 \\
\hline 100.1028 & $\mathrm{C}_{4}{ }^{13} \mathrm{C}_{2} \mathrm{H}_{12} \mathrm{~N}$ & 0.18 & 0.12 & 0.04 \\
\hline 100.1057 & $\mathrm{C}_{5}{ }^{13} \mathrm{CH}_{11}{ }^{2} \mathrm{DN}$ & 0.009 & 0.00 & 0.10 \\
\hline (3) 100.1083 & $\mathrm{C}_{4} \mathrm{H}_{12}{ }^{2} \mathrm{D}-\mathrm{N}$ & 0.0001 & 0.00 & 0.002 \\
\hline
\end{tabular}<smiles>C1CCC(=NC2CCCCC2)CC1</smiles><smiles></smiles>

B

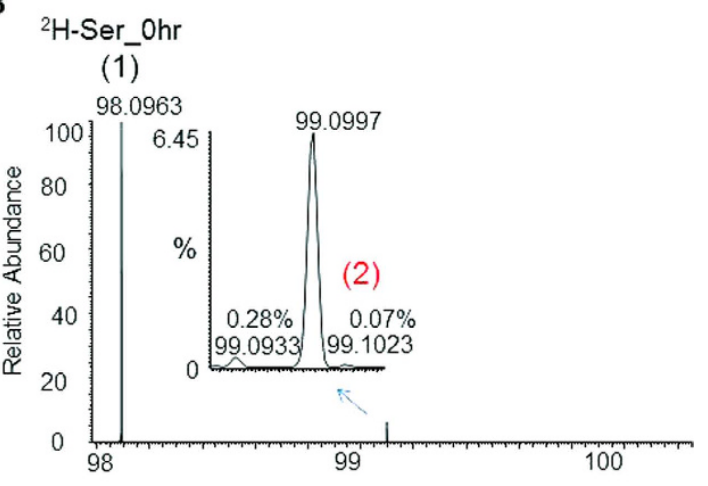

C ${ }^{2} \mathrm{H}-\mathrm{Ser}$-96hr

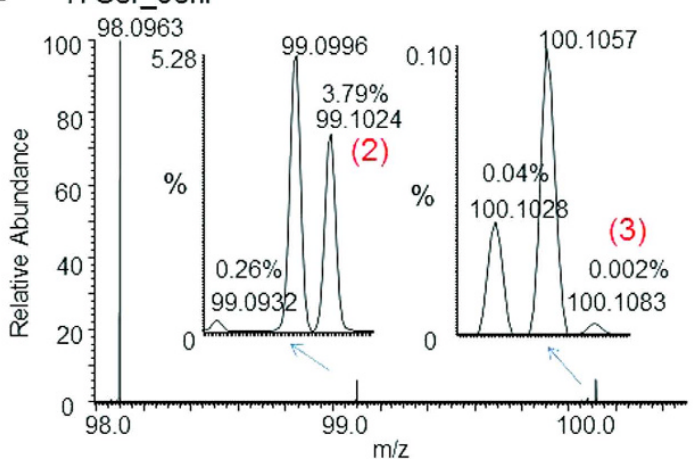

Figure 3. Monitoring of ${ }^{2} \mathrm{H}$-methyl in $\mathrm{H} 3 \mathrm{~K}$ K-mono-methyated and K14-acetylated peptides by HCD immonium ion specific to mono-methylated lysine. (A) The full HCD tandem mass spectrum of the H3 peptide; the red-colored box includes the mono-methylated lysine-specific immonium ion at $m / z 98.0963$ (1). (B) Expanded spectrum from the red-colored boxed region in A corresponding to $0 \mathrm{hr}$ of incubation with 2, $3,3-{ }^{2} \mathrm{H}$-serine. The red-colored number (2) indicates the $+1{ }^{2} \mathrm{H}$ ion. (C) Expanded spectrum from the redcolored boxed region in A corresponding to $96 \mathrm{hr}$ of incubation with 2, 3, 3-2 $\mathrm{H}$-serine. The red-colored number (3) indicates the $+2{ }^{2} \mathrm{H}$ ion. (D) A table summarizing all the isotopic ions given with their formula, calculated natural occupancy, and measured occupancy at the two time points $(0$ and $96 \mathrm{hr})$. Below the table are shown the hypothetical structures of the three immonium ions [(1) (2) and (3)] of mono-methylated lysine. To simplify the presentation, spectra at other time points are not shown.

in PMA-treated cells as compared with the controls. The data also indicated that methyl-transfer reaction rates were higher for the methylation sites in protein $\mathrm{N}$-termini $(\mathrm{H} 3 \mathrm{~K} 4 \& \mathrm{~K}$, and $\mathrm{H} 4 \mathrm{~K} 20)$ than for sites within (or close to) the protein's structural domain (H3K36 \& K79). Similar results were obtained for trimethylation at four targeted methylation sites (H4K20 and $\mathrm{H} 3 \mathrm{~K} 9, \mathrm{~K} 27$ and K36) (Fig. 5B). A decreased transmethylation rate means decreased levels of ${ }^{2} \mathrm{H}$-SAM and ${ }^{2} \mathrm{H}$-methionine generated from ${ }^{2} \mathrm{H}$-serine through the one-carbon metabolic pathway, indicating that one-carbon metabolism was impaired by PMA treatment. Taken together, our current metabolic data provide additional evidence for our previous finding that PMA down-regulates DNA replication during monocyte differentiation.

\section{Conclusion}

We have demonstrated that methyl transfer from serine to histones through the one-carbon metabolism pathways can be monitored and quantified by measuring methylation signature ions via tandem mass spectrometry. This novel method will enable the use of mass spectrometry to study one-carbon metabolism-altered histone methylation in metabolic diseases including alcohol-mediated carcinogenesis, diabetes, Alzheimer's disease, and tumor hypoxia $^{17-23}$.

\section{Methods}

As a proof-of-concept, we cultured THP1 cells for four consecutive days (d) in RPMI 1640 medium containing $0.5 \mathrm{mM} \mathrm{2}, 3,3,{ }^{2} \mathrm{H}$-serine. Briefly, cells were grown in $100 \times 15 \mathrm{~mm}$ Nunclon ${ }^{\circledR}$ cell culture dishes (Thermo Scientific) with $10 \mathrm{~mL}$ RPMI 1640 medium containing $10 \%$ FBS and $1 \%$ antibiotics and $10 \mu \mathrm{L}$ of the $0.5 \mathrm{M}$ deuterium-labeled serine stock solution. In the control dishes ( $\mathrm{d} 0 \mathrm{or} 0 \mathrm{hr}$ cells), $10 \mu \mathrm{L}$ of $0.5 \mathrm{M}$ unlabeled serine stock solution was added. The medium was changed every three days. When the cells were nearly confluent, they were pelleted and core histones extracted by acid precipitation ${ }^{24}$. Histones were re-dissolved in $200 \mu \mathrm{L}$ of deionized water, and $20 \mu \mathrm{L}$ aliquots of the histone solution were digested with $1 \mu \mathrm{l}$ of trypsin (Sigma-Aldrich) for eight hours. Histone peptides after digestion and neutralization by $1 \%$ formic acid were analyzed by LC-MS/MS on a 


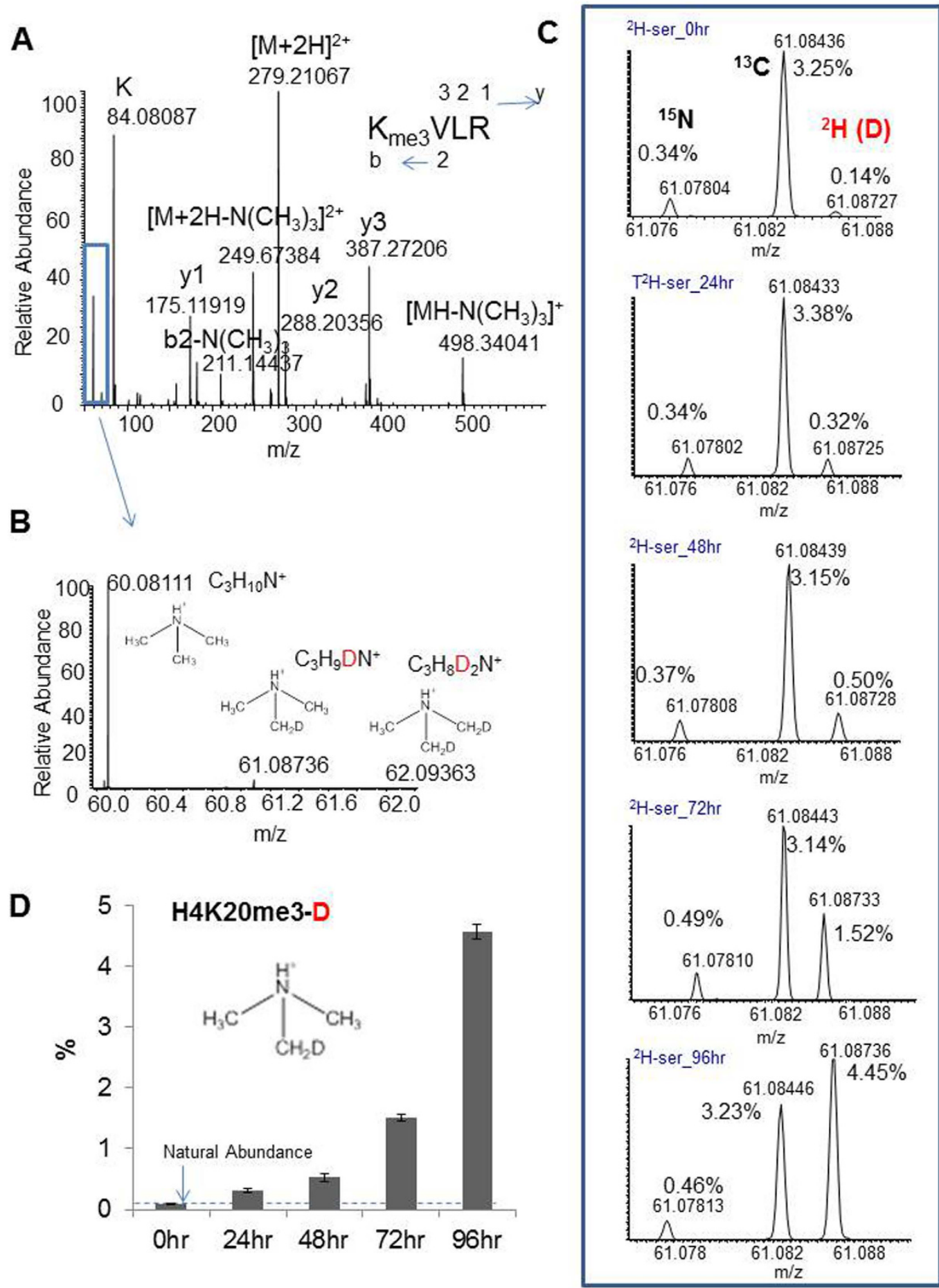

Figure 4. Monitoring the ${ }^{2} \mathrm{H}$-methyl in $\mathrm{H} 4 \mathrm{~K} 20$-tri-methyated peptide by the HCD “neutral-loss" ion specific to tri-methylated lysine. (A) The full HCD tandem mass spectrum of the H4 peptide; the blue-colored box includes the tri-methylated lysine-specific neutral-loss ion at $m / z 60.0811$. (B) Expanded spectrum from the blue-colored boxed region in A indicates +1 and $+2{ }^{2} \mathrm{H}(\mathrm{D})$ ions of histones extracted from $96 \mathrm{hr}$ incubation with $2,3,3-{ }^{2} \mathrm{H}$-serine. (C) Five spectra corresponding to the five time points $(0,24,28,72$, and $96 \mathrm{hr})$ showing the expanded +1 ions containing well-resolved ${ }^{15} \mathrm{~N},{ }^{13} \mathrm{C}$, and ${ }^{2} \mathrm{H}$ isotopes in order from left to right. (D) Bar graph showing the ${ }^{2} \mathrm{H}$-methyl transfer rate (relative percentage of the $+1{ }^{2} \mathrm{H}$ peak to the monoisotopic peak) at the five time points.

QExactive mass spectrometer with the resolution set at either 35,000 or 70,000 FWHM. The histone peptides were separated on a $15 \mathrm{~cm} \times 75 \mu \mathrm{m}$ capillary column home-packed with $3 \mu \mathrm{m}$ (pore size $120 \AA$ ) YMC-Pack ODS-AQ reverse phase material (YMC America). A Parallel-Reaction-Monitoring (PRM) method ${ }^{14,25}$ was established to 
A

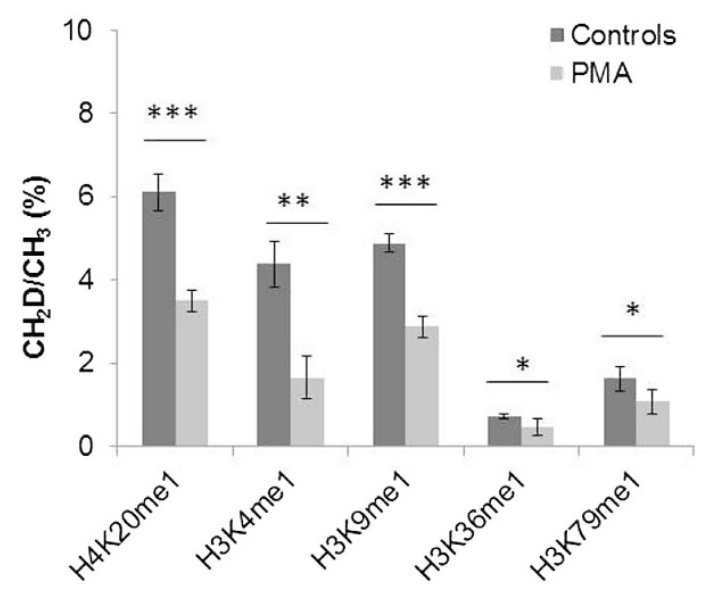

B

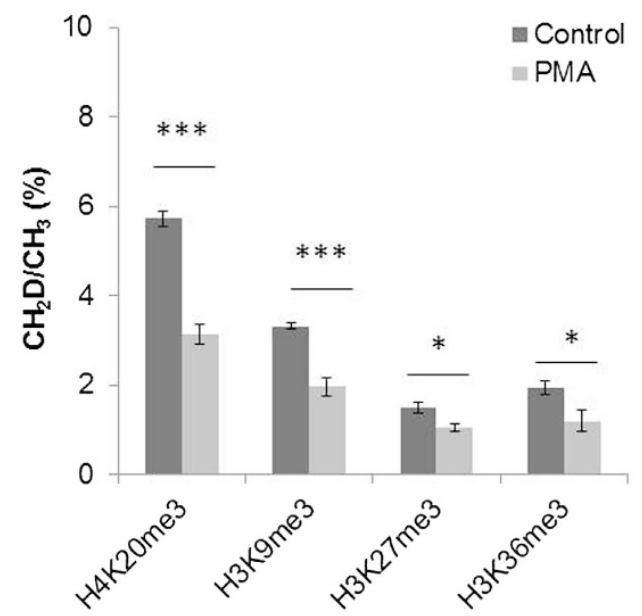

Figure 5. Decreased methyl-transfer rates from serine to histones in PMA-treated U937 cells. (A) ${ }^{2} \mathrm{H}$ (D)methyl transfer from 2, 3, 3- ${ }^{2} \mathrm{H}$-serine to histones at the indicated mono-methylation sites. (B) ${ }^{2} \mathrm{H}$ (D)-methyl transfer from $2,3,3-{ }^{2} \mathrm{H}$-serine to histones at the indicated tri-methylation sites. The data are averages from two biological repeats and four technical repeats. ${ }^{*} \mathrm{p}<0.05 ; * \mathrm{p}<0.001 ; * * \mathrm{p}<0.0001$.

target six methylations (Table S1), including histone $\mathrm{H} 3 \mathrm{~K} 4, \mathrm{~K} 9, \mathrm{~K} 27, \mathrm{~K} 36$ and $\mathrm{K} 79$, and histone $\mathrm{H} 4 \mathrm{~K} 20 .{ }^{2} \mathrm{H}-\mathrm{CH}_{3}$ was monitored by the immonium ion of mono-methylated lysine at $\mathrm{m} / \mathrm{z} 99.1024$ and by the "neutral-loss" ion of tri-methylated lysine at $\mathrm{m} / \mathrm{z} 61.0873$. The dynamics of methyl transfer can be calculated based on the relative intensities after normalization against the mono-isotope immonium ion of mono-methylated lysine or the neutral-loss ion of tri-methylated lysine on the time scale of $1 \mathrm{~d}, 2 \mathrm{~d}, 3 \mathrm{~d}$ and $4 \mathrm{~d}$. A detailed description of how to calculate methyl transfer from serine, through $1 \mathrm{C}$ metabolism, to the lysines in histones is provided in Supplemental Calculation 2.

For the monocyte cell differentiation study, we repeated our previous experiments on PMA-induced U937 cell differentiation ${ }^{16}$, with modifications. PMA is one of the well-known differentiation agents that inhibits proliferation of monocytes and converts them into M1/M2 macrophages ${ }^{26}$. Briefly, PMA-differentiated U937 cells were grown in RPMI 1640 medium containing $1 \mu \mathrm{M}$ PMA and $0.5 \mathrm{mM} 2,3,3,-{ }^{2} \mathrm{H}$-serine; control U937 cells were grown in the same medium, but containing only $0.5 \mathrm{mM} 2,3,3,-{ }^{2} \mathrm{H}$-serine and the same amount (volume) of DMSO as was used to dissolve PMA for the differentiated cells. Both control and PMA cells were grown in triplicate under identical conditions for three days before histone isolation. Histone methylation was analyzed by the above-described PRM approach to monitor the mono-methylated lysine immonium ion and the tri-methylation neutral-loss ion.

Data availability. All the instrument raw data associated with this project were deposited in PeptideAtlas (ftp://PASS00876:BI5272wv@ftp.peptideatlas.org). 


\section{References}

1. Rea, S. et al. Regulation of chromatin structure by site-specific histone H3 methyltransferases. Nature 406, 593-599 (2000).

2. Zhang, Y. \& Reinberg, D. Transcription regulation by histone methylation: interplay between different covalent modifications of the core histone tails. Genes Dev 15, 2343-2360 (2001).

3. Cantoni, G. L. The nature of the active methyl donor formed enzymatically from L-methionine and adenosinetriphosphate. J. Am. Chem. Soc. 74, 2942-2943 (1952).

4. Jones, P. A. \& Taylor, S. M. Hemimethylated duplex DNAs prepared from 5-azacytidine-treated cells. Nucleic Acids Res 9, 2933-2947 (1981).

5. Li, G. W., Burkhardt, D., Gross, C. \& Weissman, J. S. Quantifying absolute protein synthesis rates reveals principles underlying allocation of cellular resources. Cell 157, 624-635 (2014).

6. Berg, J. M., T, J. \& Stryer, L. Biochemistry. $5^{\text {th }}$ edition (2002).

7. Fox, J. T. \& Stover, P. J. Folate-mediated one-carbon metabolism. Vitam Horm 79, 1-44 (2008).

8. Locasale, J. W. Serine, glycine and one-carbon units: cancer metabolism in full circle. Nat Rev Cancer 13, 572-583 (2013).

9. Murray, K. The occurrence of e-N-methyllysine in histones. Biochemistry 3, 10-15 (1964).

10. Herring, J. L., Rogstad, D. K. \& Sowers, L. C. Enzymatic methylation of DNA in cultured human cells studied by stable isotope incorporation and mass spectrometry. Chem Res Toxicol 22, 1060-1068 (2009).

11. McAlister, G. C. et al. Increasing the multiplexing capacity of TMTs using reporter ion isotopologues with isobaric masses. Anal Chem 84, 7469-7478 (2012).

12. Merrill, A. E. et al. NeuCode labels for relative protein quantification. Mol Cell Proteomics 13, 2503-2512 (2014).

13. Watson, J. T. \& Sparkman, O. D. Introduction to Mass Spectrometry: Instrumentation, Applications, and Strategies for Data Interpretation $4^{\text {th }}$ Edition (2007).

14. Tang, H. et al. Multiplexed parallel reaction monitoring targeting histone modifications on the QExactive mass spectrometer. Anal Chem 86, 5526-5534 (2014).

15. Zhang, K. et al. Differentiation between peptides containing acetylated or tri-methylated lysines by mass spectrometry: an application for determining lysine 9 acetylation and methylation of histone H3. Proteomics 4, 1-10 (2004).

16. Xiong, L. et al. Mass spectrometric studies on epigenetic interaction networks in cell differentiation. J Biol Chem 286, 13657-13668 (2011).

17. Chang, S. C. et al. Single nucleotide polymorphisms of one-carbon metabolism and cancers of the esophagus, stomach, and liver in a Chinese population. Plos One 9, e109235 (2014).

18. Seitz, H. K. \& Stickel, F. Molecular mechanisms of alcohol-mediated carcinogenesis. Nat Rev Cancer 7, 599-612 (2007).

19. Gallou-Kabani, C. \& Junien, C. Nutritional epigenomics of metabolic syndrome: new perspective against the epidemic. Diabetes 54, 1899-1906 (2005).

20. Misiak, B., Frydecka, D., Piotrowski, P. \& Kiejna, A. The multidimensional nature of metabolic syndrome in schizophrenia: lessons from studies of one-carbon metabolism and DNA methylation. Epigenomics 5, 317-329 (2013).

21. Stover, P. J. Polymorphisms in 1-carbon metabolism, epigenetics and folate-related pathologies. J Nutrigenet Nutrigenomics 4, 293-305 (2011)

22. Martinez-Reyes, I. \& Chandel, N. S. Mitochondrial one-carbon metabolism maintains redox balance during hypoxia. Cancer Discov 4, 1371-1373 (2014).

23. Coppede, F. One-carbon metabolism and Alzheimer's disease: focus on epigenetics. Curr Genomics 11, 246-260 (2010)

24. Shechter, D., Dormann, H. L., Allis, C. D. \& Hake, S. B. Extraction, purification and analysis of histones. Nat Protoc 2, 1445-1457 (2007).

25. Sowers, J. L. et al. Quantification of histone modifications by parallel-reaction monitoring: a method validation. Anal Chem 87, 10006-10014 (2015).

26. Nicholas, D. et al. Quantitative proteomics reveals a role for epigenetic reprogramming during human monocyte differentiation. Mol Cell Proteomics 14, 15-29 (2015).

\section{Acknowledgements}

This research was partially supported by the start-up funds provided by the University of Texas Medical Branch at Galveston School of Medicine to Dr. Zhang and by NIH/NCI grant 1R01CA184097-01 to Sowers and Zhang. We thank Dr. David Konkel, UTMB Institute for Translational Sciences, for critically editing the manuscript.

\section{Author Contributions}

H.T. carried out the experiments. K.Z. designed and carried out the experiments, interpreted the data, and wrote the manuscript. B.T., A.R.B. and L.C.S. were in a collaboration team. All authors reviewed the paper.

\section{Additional Information}

Supplementary information accompanies this paper at http://www.nature.com/srep

Competing financial interests: The authors declare no competing financial interests.

How to cite this article: Tang, H. et al. Measurement of Histone Methylation Dynamics by One-Carbon Metabolic Isotope Labeling and High-energy Collisional Dissociation Methylation Signature Ion Detection. Sci. Rep. 6, 31537; doi: 10.1038/srep31537 (2016).

(c) (i) This work is licensed under a Creative Commons Attribution 4.0 International License. The images or other third party material in this article are included in the article's Creative Commons license, unless indicated otherwise in the credit line; if the material is not included under the Creative Commons license, users will need to obtain permission from the license holder to reproduce the material. To view a copy of this license, visit http://creativecommons.org/licenses/by/4.0/

(C) The Author(s) 2016 